study $10 \%$ (38) of participants unwilling or unable to stop smoking at baseline were abstinent at two years clearly gives support to the idea that smoking reduction can be a step towards abstinence.

Another caveat is that smokers who reduce their number of daily cigarettes may compensate their intake of tobacco toxins by smoking the remaining cigarettes more efficiently. The present study indicates that such compensation may occur to some extent because the reduction in carbon monoxide concentrations was lower than the corresponding reduction in cigarette consumption.

In summary, our study shows that sustained, long term reduction in smoking with the nicotine inhaler can be achieved and maintained. Smoking reduction seems a feasible first step towards improved health and may ultimately lead to complete smoking cessation in people unable or unwilling to stop smoking abruptly.

Contributors: CTB was involved in planning the study, wrote the paper, and was principal investigator for Basle.J-PZ was involved in planning the study and was principal investigator for Lausanne. TD was involved in planning, helped to write the paper, and was responsible for the trial at Pharmacia and Upjohn, Sweden. XvB was involved in planning and was the main study nurse for Basle. AR was the main study nurse for Lausanne. Å carried out the statistical analysis. APP was involved in planning and supervision during the study. US was senior study planner at Pharmacia and Upjohn, Sweden. CTB is guarantor for the study.

Funding: Pharmacia and Upjohn Consumer Healthcare, Sweden.

Competing interests: TD, ÅW, and US are all employed by Pharmacia and Upjohn, Sweden, and AR, CTB, and J-PZ have received funds for research from them.
1 Doll R, Peto R, Wheatley K, Gray R, Sutherland I. Mortality in relation to smoking: 40 years' observation on male British doctors. BMJ 1994;309:901-11.

2 Smoking Cessation Clinical Practice Guideline Panel and Staff. The agency for health care policy and research: smoking cessation clinical practice guideline. JAMA 1996;275:1270-80.

3 Benowitz NL. Pharmacology of nicotine: addiction and therapeutics. Ann Rev Pharmacol Toxicol 1996; 36:597-613.

4 Silagy C, Mant D, Fowler G, Lancaster T. Nicotine replacement therapy for smoking cessation. In: Cochrane Collaboration. Cochrane Library. Issue 3. Oxford: Update Software, 1999.

5 Paoletti P, Fornai E, Maggiorelli F, Puntoni R, Viegi G, Carrozzi L, et al Importance of baseline cotinine plasma values in smoking cessation: results from a double-blind study with nicotine patch. Eur Respir J 1996:9:643-51.

6 Kunze M. Harm reduction: the possible role of nicotine replacement. Prog Respir Res 1997;28:190-8.

7 Jiménez-Ruiz C, Kunze M, Fagerström KO. Nicotine replacement: a new approach to reducing tobacco-related harm. Eur Respir J 1998;11:473-9.

8 Fagerström KO, Tejding R, Westin A, Lunell E. Aiding reduction of smoking with nicotine replacement medications: hope for the recalcitrant smoker? Tobacco Control 1997;6:311-6.

9 DiClemente CC, Prochaska JO, Fairhurst SK, Velicer WF, Velasquez MM, Rossi JS. The process of smoking cessation: an analysis of precontemplation, contemplation, and preparation stages of change. J Consult Clin Psychol 1991;59:295-304.

10 Glasgow R, Klesges R, Klesges L, Vasey M, Gunnarson D. Long-term effects of a controlled smoking program: a two and a half year follow-up. Behav Ther 1985;16:303-7.

11 Hughes JR, Cummings M, Hyland A. Ability of smokers to reduce their smoking and its association with future smoking cessation. Addiction 1999;94:109-14

12 Tønnesen P, Nørregaard J, Mikkelsen K, Jorgensen S, Nilsson F. A double-blind trial of a nicotine inhaler for smoking cessation. JAMA 1993;269:1268-71.

13 Hjalmarson A, Nilsson F, Sjostrom L, Wiklund O. The nicotine inhaler in smoking cessation. Arch Intern Med 1997;157:1721-8.

14 Heatherton TF, Kozlowski LT, Frecker RC, Fagerström KO. The Fagerström test for nicotine dependence: a revision of the Fagerström tolerance questionnaire. Br J Addiction 1991;86:1119-27.

15 Hays RD, Sherbourne CD, Mazel RM. The RAND 36-item health surve 1.0. Health Econ 1993;2:217-77.

16 Bolliger CT. Practical experiences in smoking reduction and cessation. Addiction 2000;95(suppl 1):19-24

17 Murray RP, Bailey WC, Daniels K, Bjornson WM, Kurnow K, Connett JE, et al. Safety of nicotine polacrilex gum used by 3,094 participants in the lung health study. Chest 1996;109:438-45.

(Accepted 4 August 2000)

\title{
Effect of restrictions on smoking at home, at school, and in public places on teenage smoking: cross sectional study
}

\author{
Melanie A Wakefield, Frank J Chaloupka, Nancy J Kaufman, C Tracy Orleans, Dianne C Barker,
} Erin E Ruel

\begin{abstract}
Objective To determine the relation between extent of restrictions on smoking at home, at school, and in public places and smoking uptake and smoking prevalence among school students.

Design Cross sectional survey with merged records of extent of restrictions on smoking in public places.

Setting United States.

Participants 17287 high school students.

Main outcome measures Five point scale of smoking uptake; 30 day smoking prevalence.

Results More restrictive arrangements on smoking at home were associated with a greater likelihood of being in an earlier stage of smoking uptake $(\mathrm{P}<0.05)$ and a lower 30 day prevalence (odds ratio $0.79(95 \%$ confidence interval 0.67 to 0.91$), \mathrm{P}<0.001$ ). These findings applied even when parents were smokers. More pervasive restrictions on smoking in public places were associated with a higher probability of
\end{abstract}

being in a earlier stage of smoking uptake $(\mathrm{P}<0.05)$

and lower 30 day prevalence $(0.91$ (0.83 to 0.99 ), $\mathrm{P}=0.03)$. School smoking bans were related to a greater likelihood of being in an earlier stage of smoking uptake (0.89 (0.85 to 0.99$), \mathrm{P}<0.05)$ and lower prevalence $(0.86$ ( 0.77 to 0.94$), \mathrm{P}<0.001)$ only when the ban was strongly enforced, as measured by instances when teenagers perceived that most or all students obeyed the rule.

Conclusions These findings suggest that restrictions on smoking at home, more extensive bans on smoking in public places, and enforced bans on smoking at school may reduce teenage smoking.

\section{Introduction}

Restrictions on smoking at work and home are associated in adults with reduced daily smoking rate and increased cessation. ${ }^{1-3}$ As these types of smoking restrictions become more pervasive, ${ }^{145}$ smoking is
Correspondence to:

M A Wakefield melaniew@uic.edu

continued over

BMJ 2000;321:333-7

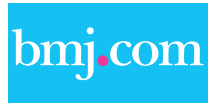

This article is part of the BMJ's randomised controlled trial of open peer review. Documentation relating to the editorial decision making process is available on the $B M J$;s website 
Health Research and Policy Centers. University of Illinois at Chicago, 850 West Jackson Boulevard, Chicago, IL 60607, USA

Melanie A

Wakefield

visiting research

scientist

Erin E Ruel

research assistant

Department of

Economics,

University of Illinois

at Chicago

Frank J Chaloupka professor

Robert Wood

Johnson

Foundation, $\mathrm{PO}$

Box 2316,

Princeton, NJ

08543, USA

Nancy J Kaufman senior vice president

C Tracy Orlean

senior scientist

Barker Bi-Coastal Health Consultants, 3556 Elm Drive, Calabasas, CA 91302, USA

Dianne C Barker principal likely to be perceived as more socially unacceptable and inconvenient. As yet, there has been little study of how smoking restrictions in public places might influence teenage use of tobacco. ${ }^{6-9}$

Banning smoking in the home, even when parents smoke, gives an unequivocal message to teenagers about the unacceptability of smoking, as do restrictions on smoking in public places. Exposure to environmental tobacco smoke during childhood has been suggested to increase tolerance for tobacco smoke and sensitise children to taking up active smoking in their teenage years by reducing the noxious deterrence of the first cigarette. ${ }^{10}$ Thus, children who are exposed more often to parents smoking inside the home might have an increased likelihood of becoming established smokers.

Schools with smoking policies have significantly lower rates of student smoking, ${ }^{11}{ }^{12}$ but although school smoking bans are common, they are poorly complied with, so enforcement is highly important. ${ }^{13}$ We sought to determine the relation between smoking restrictions in the home, at school, and in public places and measures of uptake of smoking and smoking prevalence by teenagers.

\section{Participants and methods}

The data used for this study were from a survey of United States school students in grades 9 to 12 (aged 14 to 17 years) administered in the spring of 1996 . A three stage sampling procedure was used, with the primary sampling units being counties of the mainland United States. Within each selected primary sampling unit, one school was selected with probability proportional to enrolment in grades 9 through 12 . Four reserve schools were drawn for each school in the primary sample; they were matched to selected schools by degree of urbanisation, type and size of school, percentage of children from ethnic minorities, and income level. When a selected school declined to participate, one of the matched reserve schools was asked to take part. At each selected school, one class was selected from each grade, and all students in these classes were eligible to participate in the survey. The figure shows that $73 \%$ of the schools selected as the primary or reserve sample participated in the survey and $80 \%$ of the students in sampled classes completed a survey questionnaire, yielding 17287 questionnaires. Students were informed in writing that the survey was voluntary and that responses would remain confidential. The study design and questionnaire were approved by a Robert Wood Johnson Foundation advisory panel containing independent researchers with experience in conducting youth surveys about smoking.

\section{Questionnaire measures}

Descriptors of the survey sample included sex; school grade (9-12); race (African American, Hispanic, white, other); whether adults living in the home were smokers (yes or no); and whether the respondent had siblings who smoked (yes or no). We classified respondents by stage of smoking uptake on the basis of specific responses to questions on smoking history and intentions to smoke in future that have been found to predict current smoking at follow up after three to four years. ${ }^{414}$ "Non-susceptible non-smokers" had never

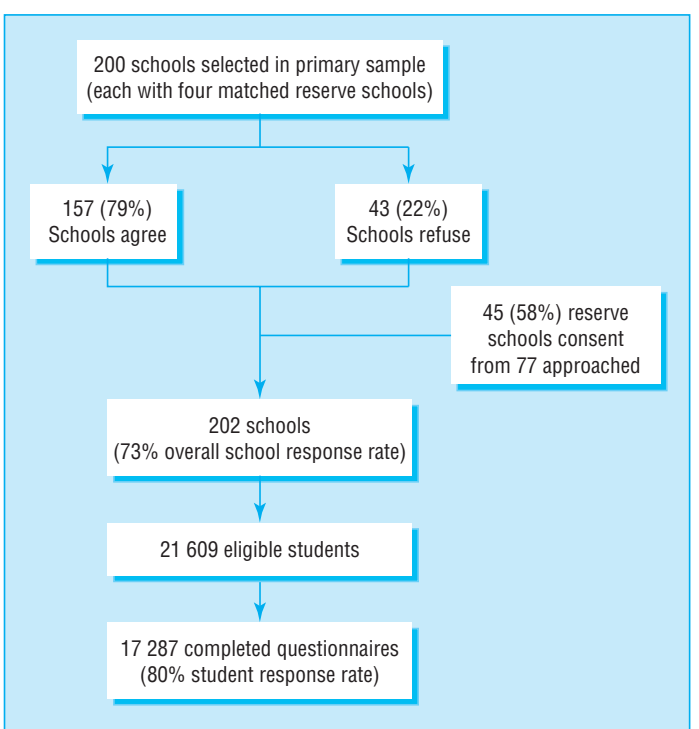

Survey sampling strategy

smoked a cigarette, even a puff, and had a strong intention not to do so in future. "Susceptible non-smokers" had never smoked a whole cigarette but had weak intentions to stay non-smokers or they had previously had a puff but had strong intentions to stay non-smokers. "Early experimenters" had puffed on a cigarette more than 30 days before the survey but had weaker intentions not to smoke in future or had smoked a whole cigarette more than 30 days before the survey and had strong intentions not to smoke in future. "Advanced experimenters" had smoked a whole cigarette more than 30 days before the survey and had weak intentions not to smoke in future or had smoked in the past 30 days but had not smoked 100 cigarettes. Irrespective of their future intentions or recent smoking activity, respondents who indicated they had smoked 100 cigarettes in their lifetime were classified as "established smokers." Current smoking was defined by the traditional measure of having smoked in the past 30 days.

Home smoking restrictions were defined by responses to the question: "how is cigarette smoking handled in your home?" with response options being a total ban ("no one is allowed to smoke in my home"), some restrictions ("only special guests are allowed to smoke in my home" or "people are allowed to smoke only in certain areas in my home"), and no restrictions ("people are allowed to smoke anywhere in my home"). Two measures of school smoking restrictions were constructed from questions which asked about whether there was a ban on smoking at their school and, if so, how many students obeyed the rule. These included whether a ban existed (school ban or no school ban) and whether a school ban was strong (most or all students comply) or weak (a ban exists but few or no students comply, or no ban).

Based on school identifiers, we added information on state, county, and city laws relating to restrictions on smoking for the 202 school sites in the survey. State laws applying in 1996 were collated from records held by the Centers for Disease Control and Prevention, ${ }^{15}$ and county and city data were acquired from databases maintained by the American Nonsmokers Rights 
Table 1 Characteristics of respondents

\begin{tabular}{|c|c|}
\hline & No (\%) \\
\hline \multicolumn{2}{|l|}{ Grade at school: } \\
\hline 9 & $3912(25.5)$ \\
\hline 10 & $4357(28.4)$ \\
\hline 11 & $3835(25.0)$ \\
\hline 12 & $3252(21.2)$ \\
\hline \multicolumn{2}{|l|}{ Sex: } \\
\hline Male & $7134(46.5)$ \\
\hline Female & $8207(53.5)$ \\
\hline \multicolumn{2}{|l|}{ Race or ethnicity: } \\
\hline White & $7226(47.1)$ \\
\hline African American & $3084(20.1)$ \\
\hline Hispanic & $3590(23.4)$ \\
\hline Other & $1457(9.5)$ \\
\hline \multicolumn{2}{|l|}{ Restrictions in public places: } \\
\hline Strong restrictions & $8760(57.1)$ \\
\hline Moderate restrictions & $2899(18.9)$ \\
\hline Weak restrictions & $3682(24.0)$ \\
\hline \multicolumn{2}{|l|}{ Restrictions at home: } \\
\hline Total ban & $7394(48.2)$ \\
\hline Some restrictions & $4173(27.2)$ \\
\hline No restrictions & $3774(24.6)$ \\
\hline \multicolumn{2}{|l|}{ School ban: } \\
\hline Ban exists & $14083(91.8)$ \\
\hline Ban does not exist & $1258(8.2)$ \\
\hline \multicolumn{2}{|l|}{ School ban enforcement: } \\
\hline Strong ban & $4342(28.3)$ \\
\hline Weak or no enforcement of ban & $10999(71.7)$ \\
\hline \multicolumn{2}{|l|}{ Stage of smoking uptake: } \\
\hline Non-susceptible non-smoker & $3954(26.4)$ \\
\hline Susceptible non-smoker & $1902(12.7)$ \\
\hline Early experimenter & $2876(19.2)$ \\
\hline Advanced experimenter & $3235(21.6)$ \\
\hline Established smoker & $3010(20.1)$ \\
\hline
\end{tabular}

Foundation in California. When county or city laws were stronger than state laws, these took precedence. We defined "strong public places restrictions" as restrictions in private worksites and restaurants, "moderate public places restrictions" as restrictions in private worksites or restaurants, and "weak public places restrictions" as neither of these environments.

\section{Statistical analysis}

We analysed data using SAS version 6.12 and MIXOR/MIXREG. ${ }^{16}$ We initially used cumulative logit analysis to examine the relation between stage of uptake and extent of restrictions but found that for some variables the proportional odds assumption was not met. Therefore, we performed a thresholds of change analysis, which allows for some variables to have varying effects on each stage of uptake of smoking. ${ }^{17}$ Since there are five stages of smoking uptake, there are four thresholds that separate these stages. Logistic regression analysis was used to examine the association between smoking status and smoking restrictions. Each analysis was adjusted for school grade, sex, whether adults at home were smokers, and whether siblings smoked. Because of the multistage sampling method we ran random effects intercepts models for each analysis to adjust our standard errors to account for the clustering. Finally, we ran a series of models that made varying assumptions about missing cases. None of these changed the pattern of findings, which indicates that there was no bias in the pattern of missing cases. ${ }^{18}$ The final number of cases for the smoking uptake analysis was 14977 and for the smoking prevalence analysis 14746.

\section{Results}

Table 1 shows the characteristics of respondents and the prevalence of smoking restrictions. In addition, $28 \%$ of teenagers (14 746) had smoked in the past 30 days. Concordance between students in their description of the status of the policy at their school was high, with $50 \%$ of schools having at least 95\% agreement and over $80 \%$ having at least $85 \%$ agreement.

Table 2 shows that smoking restrictions in public places and at home and enforced school bans were significantly associated with being in an earlier stage of smoking uptake. The relation between stage of smoking uptake and extent of restrictions on smoking in public places varied by stage. For the first two thresholds, there was no protective effect introduced by more extensive public places restrictions, but having stronger restrictions reduced the odds of the transition from early to advanced experimenter by $8 \%$ and of making the transition from advanced experimenter to established smoker by $10 \%$. Thus, more extensive restrictions on smoking in public places were associated with a lower probability of smoking uptake, but this was mostly due to reductions in the probability of transition between later, rather than earlier, stages of uptake. Home smoking restrictions had a much greater effect than bans in public places on uptake of smoking. Total bans on smoking at home exerted a relatively greater impact on transition between earlier, rather than later, stages of smoking uptake but significantly reduced the probability of transition at all thresholds. The existence of some home restrictions also reduced the likelihood of smoking uptake, but the effect was less than for total home bans, being $17 \%$ at each threshold. The existence of a ban on smoking at school was not associated with smoking uptake until the last threshold, where it was found to increase the

Table 2 Odds ratios (95\% confidence intervals) for association of restrictions with stages of smoking uptake. Odds ratios are not making comparisons with baseline level (non-susceptible non-smokers) but with previous level of smoking stage

\begin{tabular}{|c|c|c|c|c|}
\hline & $\begin{array}{c}\text { Susceptible non-smoker } \\
\text { threshold }(95 \% \mathrm{C}) \mathrm{I}\end{array}$ & $\begin{array}{l}\text { Early experimenter threshold } \\
(95 \% \mathrm{Cl})\end{array}$ & $\begin{array}{l}\text { Advanced experimenter } \\
\text { threshold }(95 \% \mathrm{Cl})\end{array}$ & $\begin{array}{l}\text { Established smoker thresholc } \\
\qquad(95 \% \mathrm{CI})\end{array}$ \\
\hline Public place restrictions & 0.96 (0.86 to 1.06$)$ & 0.93 (0.84 to 1.02$)$ & $0.92^{\star}+(0.83$ to 1.00$)$ & $0.90^{*}+(0.81$ to 0.98$)$ \\
\hline Total home ban & $0.64^{\star}(0.52$ to 0.76$)$ & $0.69^{*} \dagger(0.59$ to 0.79$)$ & $0.71^{\star} \dagger(0.60$ to 0.82$)$ & $0.78^{\star} \dagger(0.67$ to 0.90$)$ \\
\hline Some home restrictions & $0.83^{*}$ (0.74 to 0.92$)$ & $0.83^{*}$ (0.74 to 0.92$)$ & $0.83^{*}$ (0.74 to 0.92$)$ & $0.83^{*}$ (0.74 to 0.92$)$ \\
\hline School ban & 0.92 (0.77 to 1.08$)$ & 0.98 (0.85 to 1.10$)$ & $1.07(0.93$ to 1.21$)$ & $1.22^{*}+(1.07$ to 1.37$)$ \\
\hline Enforced school ban & $0.89^{*}(0.85$ to 0.99$)$ & $0.89^{*}(0.85$ to 0.99$)$ & $0.89^{*}(0.85$ to 0.99$)$ & $0.89^{*}(0.85$ to 0.99$)$ \\
\hline
\end{tabular}

$2 \log \mathrm{L}=35559.3(\mathrm{df}=57)$, intracluster correlation $=0.042$, cluster variance $=0.143, \mathrm{P}<0.0001$.

Odds ratios are adjusted for school grade, sex, race, adult smokers in home, and sibling smokers; $n=14977$.

${ }^{*}$ Odds ratio significantly different from $1.0(\mathrm{P}<0.05)$.

†Odds ratio significantly different from odds ratio at first threshold $(\mathrm{P}<0.05)$. 
Table 3 Logistic regression analysis for association of restrictions with 30 day smoking prevalence

\begin{tabular}{lcc} 
& Odds ratio $(\mathbf{9 5 \%}$ CI) & P value \\
\hline Public place restrictions & $0.91(0.83$ to 0.99$)$ & 0.03 \\
\hline Total home ban & $0.79(0.67$ to 0.91$)$ & $<0.001$ \\
\hline Some home restrictions & $0.85(0.74$ to 0.95$)$ & $<0.01$ \\
\hline School ban & $0.99(0.85$ to 1.13$)$ & 0.86 \\
\hline Enforced school ban & $0.86(0.77$ to 0.94$)$ & $<0.001$
\end{tabular}

$2 \log L=16271.0,(d f=16)$, intracluster correlation $=0.038$, cluster variance $=0.131$, $\mathrm{P}<0.0001$.

Odds ratios are adjusted for school grade, sex, race, adult smokers in home, and sibling smokers; $n=14746$.

likelihood of transition from advanced experimenter to established smoker. However, enforced school bans were associated with $11 \%$ reductions in uptake of smoking across all stages of uptake.

Table 3 shows that stronger public places restrictions had a significantly protective effect on smoking prevalence, and that home smoking restrictions had a stronger protective effect. The existence of a school ban had no effect, but strong school bans were associated with reduced smoking prevalence.

For each of the analyses, we found no significant interactions between parental smoking and home bans, or between bans in different environments, on the smoking outcome variables.

\section{Discussion}

Our study of the relation between smoking restrictions in a range of environments and smoking behaviour of teenagers suggests that restrictions in the home and public places and enforced bans in schools have a protective effect on teenage smoking. These findings are subject to at least four limitations. Firstly, our data are from a cross sectional survey, which limits attributions about the direction of causality between variables. There may be other factors that influence teenage smoking apart from restrictions on smoking, and these could lead to an artificial relation between restrictions and youth smoking. For example, in places where stronger restrictions exist on smoking in public places, the environment for tobacco control may be more favourable and there may be other policy influences that promote lower smoking rates by teenagers. We

\section{What is already known on this topic}

Restrictions on smoking at home and in public places reduce levels of smoking in adults

Such restrictions are becoming more common

\section{What this study adds}

Transition of teenagers through stages of taking up smoking was reduced by bans on anyone smoking at home and also by restrictions on home smoking

Bans in public places also reduced smoking uptake but had less effect than home bans

Smoking bans in schools had little effect unless strongly enforced have not controlled for such factors. However, we did control for adult smoking, which is also likely to be influenced by these policies, and found little change in the model variables and no interactions with adult smoking. Nevertheless, our findings require further examination in longitudinal studies.

Secondly, we used a previously untested three point measure for extensiveness of public places laws. Preliminary analyses with a five point scale developed in the $1980 \mathrm{~s}^{819}$ produced a similar pattern of findings, although we were concerned about using the older scale because it produced a ceiling effect, with most cases lying in the strongest possible level. Our three point measure better captured the progress that has been made over the past decade in implementing restrictions on smoking in public places.

Thirdly, we had no information about the duration of the restrictions in any of the environments we examined, and it may be that effects change over time as teenagers accommodate to a more restrictive environment. Finally, we did not have measures of actual enforcement of, or compliance with, laws restricting smoking in public places. However, studies of restrictions on smoking at work and in other public places such as restaurants suggest that they have high levels of compliance..$^{0-23}$

Notwithstanding these cautions, our finding that home smoking bans reduce smoking uptake and prevalence is consistent with other research. Studies in Europe and the United States have shown that parental opposition to smoking and setting clear standards about smoking are more important predictors of teenagers' intentions to smoke than is parental smoking behaviour. ${ }^{24-26}$ Our results apply both where parents do and do not smoke, suggesting that even if parents are unable to quit smoking to set a good example for their children, banning smoking in the home may reduce the likelihood of teenagers taking up smoking. By comparison, stronger restrictions in public places are likely to have a more modest effect.

Finally, school bans had a protective effect on teenage smoking only when they were strongly enforced. This is generally consistent with the literature and highlights the importance of enforcing smoke-free policies in schools. ${ }^{11-13}$

Contributors: MAW conceived of and supervised the analysis and led the writing of the paper. FJC helped conceive the study and analyse the data and participated in writing the paper. NJK, CTO, and DCB planned and supervised the survey and participated in writing the paper. EER analysed the data and participated in writing the paper. Don Hedeker provided statistical advice. MAW is the study guarantor.

Funding: Supported by grants from Robert Wood Johnson Foundation to the National Bureau of Economic Research (the impact of environmental factors on youth and young adult tobacco use) and the University of Illinois at Chicago (ImpacTeen-a policy research partnership to reduce youth substance use).

Competing interests: None declared.

Chapman S, Borland R, Scollo M, Brownson RC, Dominello A, Woodward S. The impact of smoke-free workplaces on declining cigarette consumption in Australia and the United States. Am J Public cigarette consumption in

2 Farkas AJ, Gilpin EA, Distefan JM, Pierce JP. The effects of household and workplace smoking restrictions on quitting behaviors. Tobacco Control 1999;8:261-5.

3 Gilpin EA, White MM, Farkas AJ, Pierce JP. Home smoking restrictions: which smokers have them and how they are associated with smoking behavior. Nicotine Tobacco Res 1999;1:153-62. 
4 Pierce JP, Gilpin EA, Emery SL, Farkas AJ, Zhu SH, Choi WS, et al. Tobacco control in California: who's winning the war? An evaluation of the tobacco control program, 1989-1996. La Jolla, CA: University of California, San Diego, 1998. http://ssdc.ucsd.edu/tobacco/reports/

5 Borland R, Mullins R, Trotter L, White V. Trends in environmental tobacco smoke restrictions in the home in Victoria, Australia. Tobacco Control 1999:8:266-71.

6 Wasserman J, Manning WG, Newhouse JP, Winkler JD. The effects of excise taxes and regulations on cigarette smoking. $J$ Health Econ 1991;10:43-64.

7 Chaloupka FJ, Grossman M. Price, tobacco control policies and youth smoking. Cambridge, MA: National Bureau of Economic Research, 1996. (Working papers No 5740.) http://papers.nber.org/papers/W5740

8 Tauras JA, Chaloupka FJ. Clean indoor air, and cigarette smoking: evidence from the longitudinal data for young adults. Cambridge, MA: National Bureau of Economic Research, 1999. (Working paper No 6937.) http:// papers.nber.org/papers/W6937

9 Biener L, Cullen D, Xiao Z, Hammond SK. Household smoking restrictions and adolescent's exposure to environmental tobacco smoke. Prew Med 1997;26:358-63.

10 Flay B. Youth tobacco use: risks, patterns and control. In: CT Orleans, J Slade, eds. Nicotine addiction:principles and management. New York: Oxford University Press, 1993:365-84.

11 Pentz MA, Dwyer JH, MacKinnon DP, Flay BR, Hansen WB, Wang EY, et al. A multicommunity trial for primary prevention of adolescent drug abuse. JAMA 1989;261:3259-66.

12 Charlton A, While D. Smoking prevalence among 16-19 year olds related to staff and student smoking policies in sixth forms and further education. Health Educ J 1994;53:191-215.

13 Pentz MA, Sussman S, Newman T. The conflict between least harm and no-use tobacco policy for youth: ethical and policy implications. Addiction 1997:92:1165-73.

14 Pierce JP, Choi WS, Gilpin EA, Farkas AJ, Merritt RK. Validation of susceptibility as a predictor of which adolescents take up smoking in the United States. Health Psychol 1996;15:355-61.

15 Office on Smoking and Health. State tobacco activities tracking and evalua tion system. Atlanta, GA: Centers for Disease Control and Prevention,
Department of Health and Human Services. www2.cdc.gov/nccdphp/ osh/state/index.htm (accessed 23 June 2000)

16 Hedeker D, Gibbons RD. MIXOR/MIXREG: programs for mixed-effects linear regression and mixed-effects logistic regression with ordinal outcomes. www.uic.edu/ hedeker/mixreg.html (accessed 23 June 2000)

17 Hedeker D, Mermelstein RJ. A multilevel thresholds of change model for analysis of stages of change data. Multivariate Behavioral Res 1998;33:427-55.

18 Wakefield M, Chaloupka F, Kaufman N, Orleans CT, Ruel E. Do smoking restrictions at home, at school and in public places, influence youth smoking? Chicago, IL: University of Illinois, 2000. (ImpacTeen working paper series No 3.) (http://www.uic.edu/ hedeker/mixreg.html)

19 Emont SL, Choi WS, Novotny TE, Giovino GA. Clean indoor air legislation, taxation and smoking behavior in the United States: an ecological analysis. Tobacco Control 1992;2:13-7.

20 Hocking B, Borland R, Owen N. A total ban is acceptable and effective. J Occup Med 1991;33:163-7.

21 Wakefield M, Roberts L, Owen N. Trends in prevalence and acceptance of workplace smoking bans among indoor workers in South Australia. Tobacco Control 1996:5.205-8.

22 Hyland A, Cummings KM, Wilson MP. Compliance with the New York City Smoke-Free Air Act. J Public Health Manag Pract 1999;5:22-7.

23 Jacobsen PD, Wasserman J. The implementation and enforcement of tobacco control laws: policy implications for activists and the industry. $J$ Health Polit Policy Law 1999:24:567-98.

24 Aaro L, Hauknes A, Berglund E. Smoking among Norwegian schoolchildren 1975-1980. 2. The influence of the social environment. Scand J Psychol 1981;22:297-309.

25 Eiser JR, Morgan M, Gammage P, Gray E. Adolescent smoking: attitudes, norms and parental influence. Br J Soc Psychol 1989;28:193-202.

26 Mermelstein R and the Tobacco Control Network Writing Group. Explanations of ethnic and gender differences in youth smoking: a multisite, qualitative investigation. Nicotine Tobacco Res 1999;1:S91-8.

(Accepted 9 June 2000)

\section{Effect of counselling mothers on their children's exposure to environmental tobacco smoke: randomised controlled trial}

Melbourne F Hovell, Joy M Zakarian, Georg E Matt, C Richard Hofstetter, J Thomas Bernert, James Pirkle

\begin{abstract}
Objective To test the efficacy of behavioural counselling for smoking mothers in reducing young children's exposure to environmental tobacco smoke. Design Randomised double blind controlled trial. Setting Low income homes in San Diego county, California.

Participants 108 ethnically diverse mothers who exposed their children (aged $<4$ years) to tobacco smoke in the home.

Intervention Mothers were given seven counselling sessions over three months.

Main outcome measures Children's reported exposure to environmental tobacco smoke from mothers in the home and from all sources; children's cotinine concentrations in urine.

Results Mothers' reports of children's exposure to their smoke in the home declined in the counselled group from 27.30 cigarettes/week at baseline, to 4.47 at three months, to 3.66 at 12 months and in the controls from 24.56 , to 12.08 , to 8.38 . The differences between the groups by time were significant $(\mathrm{P}=0.002)$. Reported exposure to smoke from all sources showed similar declines, with significant differences between groups by time $(P=0.008)$. At 12
\end{abstract}

months, the reported exposure in the counselled group was $41.2 \%$ that of controls for mothers' smoke (95\% confidence interval $34.2 \%$ to $48.3 \%$ ) and was $45.7 \%$ (38.4\% to $53.0 \%)$ that of controls for all sources of smoke. Children's mean urine cotinine concentrations decreased slightly in the counselled group from $10.93 \mathrm{ng} / \mathrm{ml}$ at baseline to $10.47 \mathrm{ng} / \mathrm{ml}$ at 12 months but increased in the controls from 9.43 $\mathrm{ng} / \mathrm{ml}$ to $17.47 \mathrm{ng} / \mathrm{ml}$ (differences between groups by time $\mathrm{P}=0.008$ ). At 12 months the cotinine concentration in the counselled group was $55.6 \%$ $(48.2 \%$ to $63.0 \%)$ that of controls.

Conclusions Counselling was effective in reducing children's exposure to environmental tobacco smoke. Similar counselling in medical and social services might protect millions of children from environmental tobacco smoke in their homes.

\section{Introduction}

The World Health Organization has estimated that the health of almost half of the world's children is threatened by exposure to environmental tobacco smoke. ${ }^{1}$ In the United States the prevalence of US children living in homes with a smoker has been estimated to be $43 \%$, with state specific estimates of exposure in
USA

Melbourne F Hovell professor

Joy M Zakarian

senior research

associate

Georg E Matt

professor

C Richard

Hofstetter

professor

continued over

BMJ 2000;321:337-42 